\section{DUODENAL ULCER}

Observations on 250 Cases, with Special Reference

to THE TYPes OF THE STOMACH AND THE Corresponding Test Meal Findings

BY

H. SEAWARD MORLEY, M.D., M.R.C.P.

PHYSICIAN TO THE ROYAL WEST SUSSEx hospital, CHICHESTER : CLINICAL ASSISTANT AND LATE MEDICAL REGISTRAR, UNIVERSITY COLLEGE HOSPITAL

\section{(With Special Plate)}

The following investigation was carried out in an effort to discover whether there appeared to be any definite type of stomach, as shown radiographically, which was most often associated with duodenal ulceration ; and, secondly, whether there was any obvious correlation between the type of the stomach in duodenal ulcer and the test meal curves obtained in each variety.

The case records of patients admitted to the medical wards of University College Hospital during the years 1927-31 form the material on which the investigation is based. The series comprises 200 cases of clinical and radiographic duodenal ulceration, and $\mathbf{5 0}$ further cases in which operation subsequently confirmed the presence of an ulcer. Cases in which pyloric obstruction or dilatation of the stomach was present have been excluded.

Sex.-The sex ratio, as has often been noted, gave a high preponderance of males-5.2 males to 1 female. Moynihan, ${ }^{1}$ in a series of cases, gives the proportions as 493 males to 98 females, or 4.4 to 1 , and in 126 cases Hurst $^{2}$ gives the proportion as 4.6 to 1 .

Age.-The average age of the patients when symptoms first occurred was 36 years. If, however, the percentages at the various decades are taken, one-third of all cases first showed symptoms between the ages of 20 and 29 years, and more than one-half between 20 and 39 years.

\begin{tabular}{cccccccc}
\multicolumn{1}{c}{ Age Incidence of First } & Occurrence of Sy'mptoms \\
$0-9$ & $10-19$ & $20-29$ & $30-39$ & $40-49$ & $50-59$ & 6069 & $70-79$ \\
$0 \%$ & $7.4 \%$ & $33.3 \%$ & $20.3 \%$ & $19.6 \%$ & $10.3 \%$ & $6.4 \%$ & $2.7 \%$
\end{tabular}

The majority had had symptoms for five to ten years or more, the average age on admission being 42.5 years. Ryle, ${ }^{9}$ in his recent Hunterian Lecture, gives the average age on consultation as 47 years.

Incidence of Pain.-The average incidence of pain was one and three-quarter hours after food.

\section{The Type of Stomach Involved}

A standard barium meal was given in each case and an immediate $x$-ray film taken in the erect position. The shaps of the stomach, the position of the pylorus, and the level of the lowest point of the lesser curvature were noted in assessing the type of the stomach.

Broadly speaking, stomachs may be divided into the steerhorn type of Holzknecht, where the lesser curvature forms a continuous diagonal falling curve from the cardiac to the pyloric end, and the " J "-shaped stomach, where the lesser curvature descends relatively vertically and rises with an acute angle to reach the pylorus.

Mills ${ }^{4}$ grouped the types of stomach into four categories: hypersthenic, where the stomach is of the steerhorn type and lies high in the abdomen and almost transversely; sthenic, where the stomach is still of the steerhorn type, but is otherwise normal in position; hyposthenic, where the stomach is " $\mathrm{J}$ "-shaped, but normal in position ; and asthenic, in which the " $\mathrm{J}$ "-shaped stomach is abnormally low in position. Each of these classes is associated with a type of individual, and is normal for that particular build. Magnus Redding, ${ }^{3}$ using the same classification, takes the lowest point of the lesser curvature as the deciding factor. Cases in which the lesser curvature was more than $1 \frac{1}{2}$ inches above the iliac crests were classed as hypersthenic, where this was $1 / 2$ to $1 \frac{1}{2}$ inches above the intercristal line as sthenic, at or about the iliac crest as hyposthenic, and when definitely below this line as asthenic. It must be clearly understood that the terms " hyposthenic" and " hypersthenic" refer to the build of the patient and consequent shape of the stomach, while " hypotonus" and " hypertonus" refer to the tone of the stomach, for a hyposthenic stomach may be hypertonic.

It is realized that in some cases of duodenal ulcer the eventual delayed emptying of the stomach owing to pyloric hypertonus leads to some dilatation, which is very moderate in degree and in no way comparable to a similar condition occurring in organic obstruction of the pylorus; but it is surprising how little this interferes with the recognition of the original shape of the stomach, which can be quite easily identified.

When dilatation occurs the radiogram of a barium meal shows an increase in the transverse measurement of the stomach, due largely to sagging of the greater curvature, and the column of barium is not adequately held up in the proximal portion. Not more than 5 to 10 per cent. of the total number of cases of duodenal ulcer admitted during the period under review were of such nature, and these cases were not included in the series.

There must be at times some slight difficulty in deciding into which category the stomach should be placed, and borderline cases, of course, occur ; but, taking into consideration the shape of the stomach, the position of the pylorus relative to the umbilical level, and the lowest point of the lesser curvature, as compared to the plane of the iliac crests, the majority of $x$-ray films can be classified readily. As an illustration of the more typical appearances 'of the four types the radiogram of a case of each variety is reproduced on the plate.

The frequency of the incidence of the four types of stomach in 100 normal individuals is given by Mills ${ }^{4}$ as: hypersthenic, 5 per cent. ; sthenic, 48 per cent. ; hyposthenic, 35 per cent. ; asthenic, 12 per cent.

In the complete series of cases the percentages were found to be: hypersthenic, 7.8 per cent. ; sthenic, 44.4 per cent.; hyposthenic, 46.8 per cent. ; asthenic, 1 per cent.

In the $\mathbf{5 0}$ cases in which a duodenal ulcer was subsequently found at operation the percentages were: hypersthenic, 5.5 ; sthenic, 44.2 ; hyposthenic, 50.3.

In 50 cases in which clinical and radiographic evidence is, in addition, strengthened by the presence of occult blood in the stools the percentages were: hypersthenic, 9.7 ; sthenic, 39 ; hyposthenic, $\mathbf{5 1 . 3 .}$

It will be seen that there was a slightly greater preponderance of the hyposthenic type and a reduction in the asthenic variety. In general, it may be said that the proportions closely follow the normal percentages of the various types in a hundred normal individuals as given by Mills, and would suggest that the form of the stomach has no great bearing on its liability to duodenal ulceration.

\section{Test Meal Findings}

Amount of Secretion.-The following average amount of resting juice was found: all cases, $32 \mathrm{c.cm}$. ; hyposthenic type, $30 \mathrm{c.cm}$. ; sthenic type, $31.5 \mathrm{c.cm}$. ; hypersthenic type, $52.5 \mathrm{c} . \mathrm{cm}$. This tends to support the view that there is a tendency to hypersecretion in the hypersthenic type. After removing samples of approximately 5 to $10 \mathrm{c.cm}$. every quarter of an hour, at the end of three hours there was the following residue: all cases, $27.7 \mathrm{c} . \mathrm{cm}$.; hyposthenic type, $33 \mathrm{c.cm}$. ; sthenic type, $23 \mathrm{c.cm}$. ; hypersthenic type, 20 c.cm. 
- Form of the Curve.-Roughly speaking, the form of the test meal curve may be divided into the rising type, the plateau type, and the type in which a rise is followed by a fall. Dividing them thus, the following results were obtained:

$$
\begin{aligned}
& \text { All cases } \quad . .61 \text { Rising } \quad \text { Plateat Rise and fall } \\
& \begin{array}{lllllll}
\ldots & 23.0 \% & \ldots \ldots & 57.0 \% & \ldots \ldots & 20.0 \%
\end{array} \\
& \begin{array}{llllllll}
\text { Sthenic } & \ldots & \ldots & 20.5 \% & \ldots \ldots & 36.0 \% & \ldots . . & 43.5 \%
\end{array} \\
& \begin{array}{lllllll}
\text { Hypersthenic } & \ldots & 12.5 \% & \ldots \ldots . & 37.5 \% & \ldots \ldots . & 50.0 \%
\end{array}
\end{aligned}
$$

The average test meal curve compounded from the figures of all cases shows, after the initial fall, a steady rise up to one hour, followed by a plateau and a slight fall after two hours.

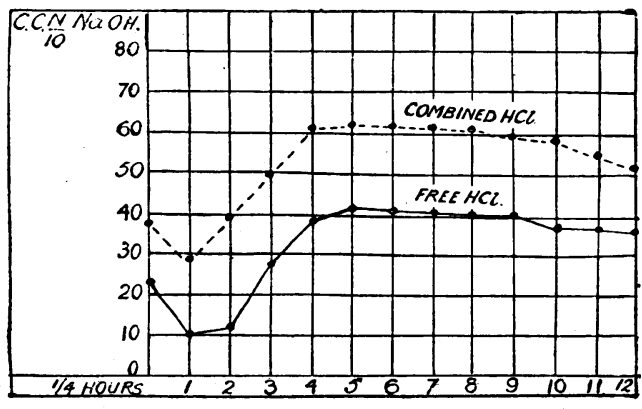

Chart 1. - All cases.

A similar curve is obtained in the cases confirmed afterwards at operation.

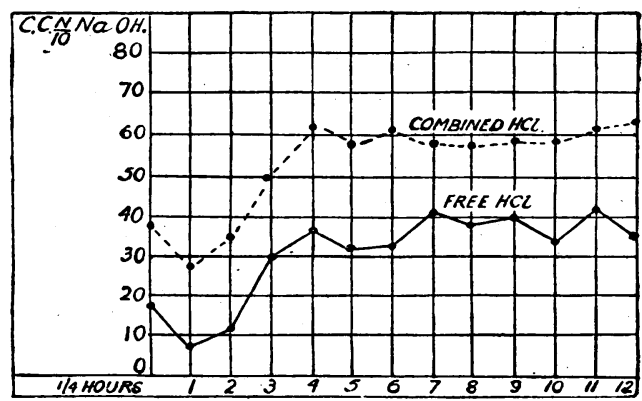

Chart 2.-Operation cases: duodenal ulcer found.

The curve roughly agrees with that given by Donald Hunter, ${ }^{7}$ but is lower than that given by Ryle. ${ }^{8}$

The curve of free $\mathrm{HCl}$ is definitely above the average of the normal limits of free $\mathrm{HCl}$ as found by Bennett and Ryle $^{10}$ in 80 per cent. of 100 normal males.

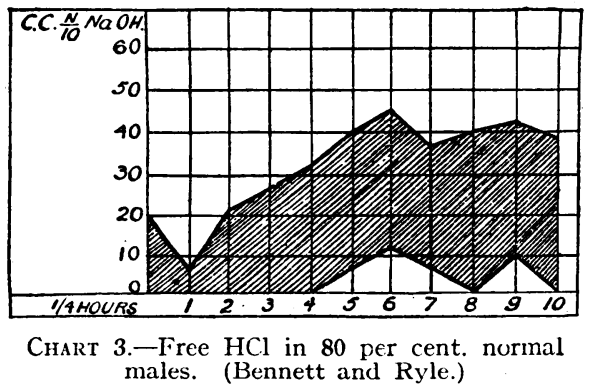

As regards the correlation between the type of stomach and the average test meal curve found in each variety it was observed that the curve of gastric acidity was lowest in the asthenic type, and gradually rose until the hypersthenic $t_{y p e}$ showed the greatest acidity (see Charts $4,5,6,7)$.

These results tend to show that there is some correlation between the type of the stomach and the curve of gastric secretion, the hypersthenic stomach having the highest curve. In all cases there tends to be an increased acidity above the normal, which agrees with the views of most authorities that this factor is usually present in duodenal ulceration.

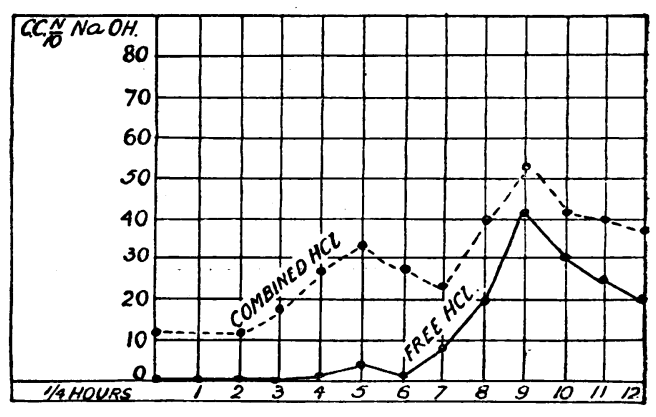

Chart 4.-Asthenic type.

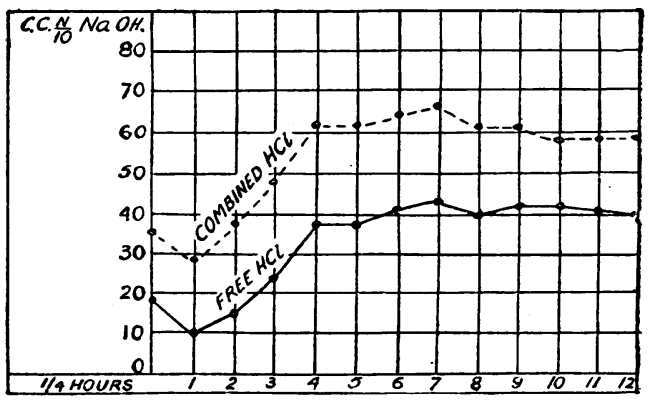

Chart 5.-Hypesthenic type.

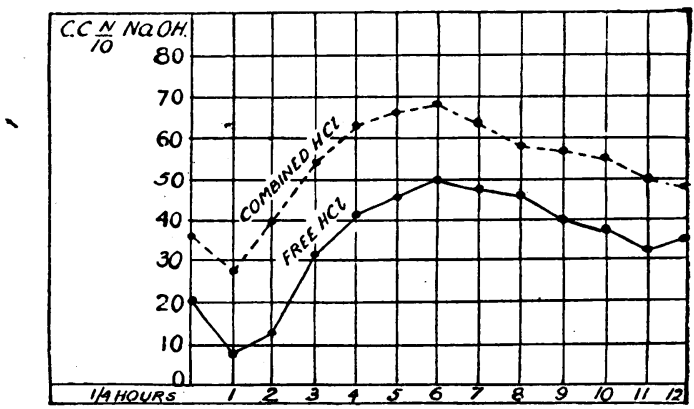

Chart 6.-Sthenic type.

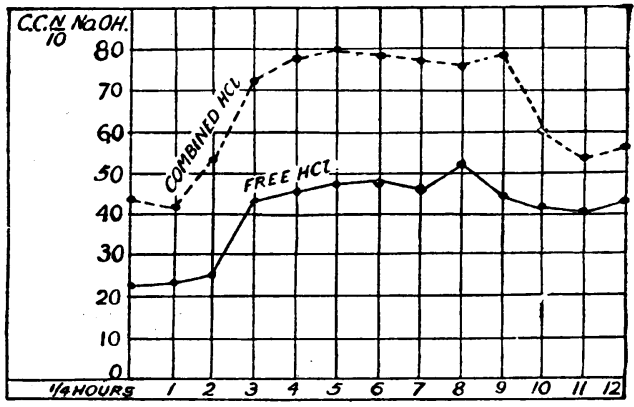

CHART 7.-Hypersthenic type.

SUMMARY

The records of 250 cases of probable duodenal ulceration have been investigated and the following deductions drawn:

1. The sex incidence shows a preponderance of $\mathbf{5 . 2}$ males to 1 female.

2. One-third of all cases first notice symptoms between the ages of 20 and 29 ; more than one-half between 20 and 39 years of age. 
3. The asthenic type of stomach is infrequently the seat of duodenal ulceration; but otherwise duodenal ulcers occur in the hyposthenic, sthenic, and hypersthenic types in about the same proportions as these types occur in a hundred normal individuals.

4. The average test meal curve is higher in cases of duodenal ulceration than in normal individuals.

5. The curve of gastric acidity steadily increases from being lowest in the asthenic to a maximum in the hypersthenic type.

I am much indebted to Dr. Charles Bolton for his help and suggestions in carrying out this investigation, to $\mathrm{Dr}$. G. W. Goodhart for permission to use the test meal curves, to Dr. Salmond and the staff of the Radiographic Department of University College Hospital for the use of their radiograms, and to the physicians under whose care the patients were treated for permission to use the records.

REFERENCES

Moynihan, Lord: British Medical Journal, 1923, i, 221.

Hurst, A. F.: Gastric and Duodenul Ulcers.

${ }^{3}$ Redding, Magnus: X-ray Diagnosis.

${ }^{4}$ Mills, K. W.: Amer, Journ. Roentgen., 1917, iv, 155.

5 Hurst, A. F.: Lancet, 1922, ii, 1369.

${ }^{-}$Carman, R. D.:Roentgen Diagnosis of Discases of the Alimentary Canal, p. 135.

'Hunter, Donald: Quart. Journ. Med., 1923, xvi, 95.

8 Ryle, J. A.: Lancet, April 4th, 1925.

- Idem: Ibid., February 13th, 1932.

${ }^{20}$ Bennett and Ryle: Guy's Hospital Reports, 1921, lxxi, No. 3, 317.

\section{EXCRETION UROGRAPHY *}

$$
\text { BY }
$$

REGINALD T. PAYNE, M.B., B.S., F.R.C.S:

$$
\text { (With Special Plate) }
$$

There are few parts of the human body where localization of the extent and nature of diseased processes can be carried out with such a high degree of accuracy as in the urinary tract. Certainly in no other system does accurate localization so constantly indicate the possibilities of surgical treatment. For this accuracy of diagnosis urology has owed much to radiology, and without its help advance would have been impossible. In this respect the year 1906 was a memorable one, for it was then that the first successful pyelography was carried out by Professor Voelker upon Alexander von Lichtenberg. Since that time there have been many modifications and improvements in the technique of carrying out instrumental urography. But all these methods have involved cystoscopy, and in the case of ureterography and pyelography have involved, in addition, the passage of ureteric catheters. The main improvements have been technical ones, and those relating to the type of material used as opaque media. With these instrumental methods, however, great advances have been made in the diagnosis of affections of the urinary tract. In the kidney, pyelography has permitted the localization of stone, and the demonstration of the configuration of the calyces and pelvis in inflammation, hydronephrosis, and new growth, to mention but a few examples. In the ureter, its course, shape, and relation to doubtful shadows in the neighbourhood have been demonstrated. In the bladder, cystography has been of great use in the demonstration of diverticula. Such radiographic methods of demonstration in the urinary tract are instrumental ones. Excretion urography, on the other hand, is the demonstration of the urinary tract by the intravenous injection of drugs which are excreted in a concentrated form in the urine-drugs which are, in addition, opaque, and in consequence of this property the outline of the urinary tract can be demonstrated during their excretion.

* Abstract of Hunterian Lecture delivered before the Royal College of Surgeons of England on February 3rd.
Historical Aspects

At about the same time as the introduction of instrumental pyelography Voelker and von Lichtenberg attempted the experimental production of excretion urograms by the use of the colloidal heavy metals, but found that these were too toxic. Following this, and partly due to the successful development of instrumental methods, further investigations were in abeyance for some years. In the year 1923 Osborne, Sutherland, Rowntree, and Scholl, by means of the intravenous injection of a solution of sodium iodide, were able to obtain quite satisfactory cystograms, together with a suggestion of opacities in the region of the renal pelves. They thus proved that excretion urography was a possibility, and that success awaited the discovery of an appropriate contrast medium. Following this, a large amount of experimental work was carried out in animals in the search for a contrast medium which would be excreted in suffcient concentration to give good pictures. It was, however, Roseno who advanced the problem a step further. This worker conceived the idea of using a combination of urea and sodium iodide, known as pyelgnost. After intravenous injection of this drug radiographic shadows of the urinary tract were obtained, but frequently toxic effects were produced, and in many cases the density of the resulting pictures was insufficient for clinical purposes.

Finally, the greatest stimulus to renewed effort was the success which attended Graham's discovery of cholecystography. The search for an adequate medium for urography came in 1929 as the result of much painstaking work in chemical synthesis, biological assay, and clinical trial.

\section{Choice of Drugs}

From the chemical standpoint the credit of first synthesizing satisfactory drugs for excretion urography belongs to Professor Binz of Berlin, a pupil of Ehrlich. With the help of Professor Raeth some seventy-three drugs related to the pyridine series and containing iodine were synthesized. After animal experiments, the clinical investigations with certain of these drugs were carried out by Professor Alexander von Lichtenberg and his assistant Swick at St. Hedwig's Krankenhaus in Berlin. Since that time many other drugs have been introduced and tried clinically. The three drugs now on the market and in current use are uroselectan, abrodil, and uroselectan B.

Uroselectan.-This is a pyridine compound containing 42 per cent. of organically bound iodine ; 40 grams of the freshly prepared drug is given intravenously in $100 \mathrm{c.cm}$. of water, corresponding to 17 grams of iodine. The drug is stable, non-toxic, is eliminated through the kidneys to the extent of 85 per cent., and its presence can be determined in the blood some four hours or more after injection, the length of time depending upon the functional capacity of the kidneys.

Abrodil.-This is sodium-iodo-methane-sulphonate. Its iodine content is $\mathbf{5 2}$ per cent. ; it is $\mathbf{7 0}$ per cent. soluble in water, and is available as a sterile solution of 20 grams in $50 \mathrm{c} . \mathrm{cm}$. of water; 86 per cent. of the drug is eliminated in the urine.

Uroselectan B.-This also is a derivative of the iodinepyridine series. In actual practice it has considerable advantages over the above-mentioned. Although only some 63 per cent. is eliminated through the kidneys, this occurs much more rapidly and with much less diuresis than with the other drugs, so that the concentration in the urine is 7.94 per cent. Its iodine content is 51 per cent. A great advantage is the fact that only $20 \mathrm{c.cm}$. of fluid, containing 15 grams of uroselectan $B$, need be injected.

It is impossible here to enter into the many technical questions which are concerned with these drugs. With all of them the success of the resulting pictures depends 
H. SEAWARD MORLEY : DUODENAL ULCER : TYPES OF STOMACH

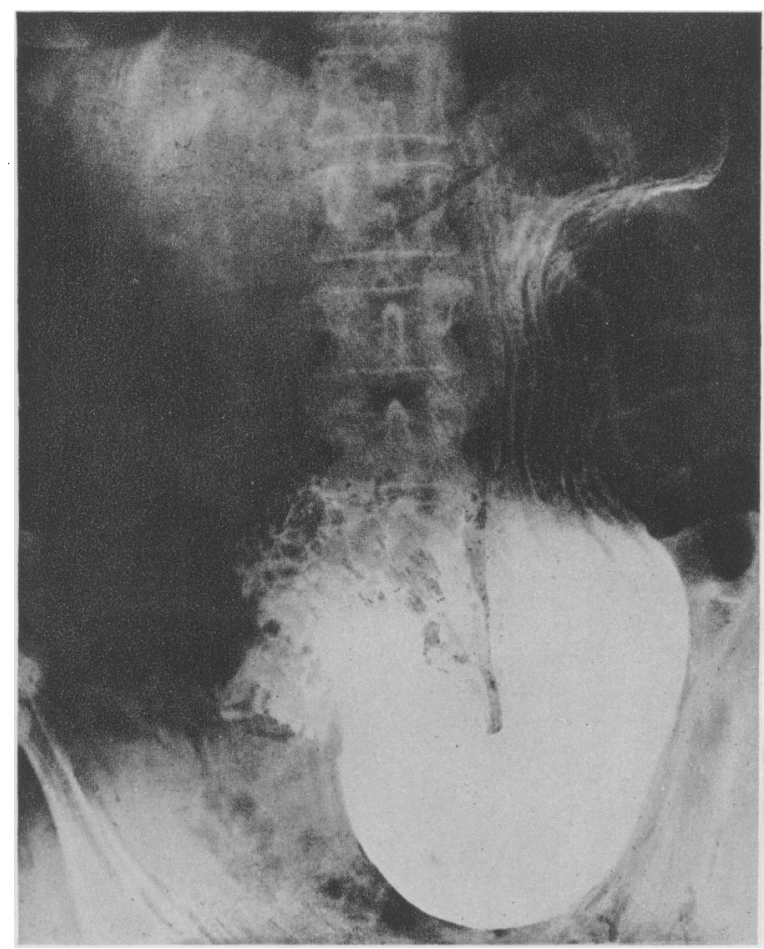

Fia 1.-Asthenic type.

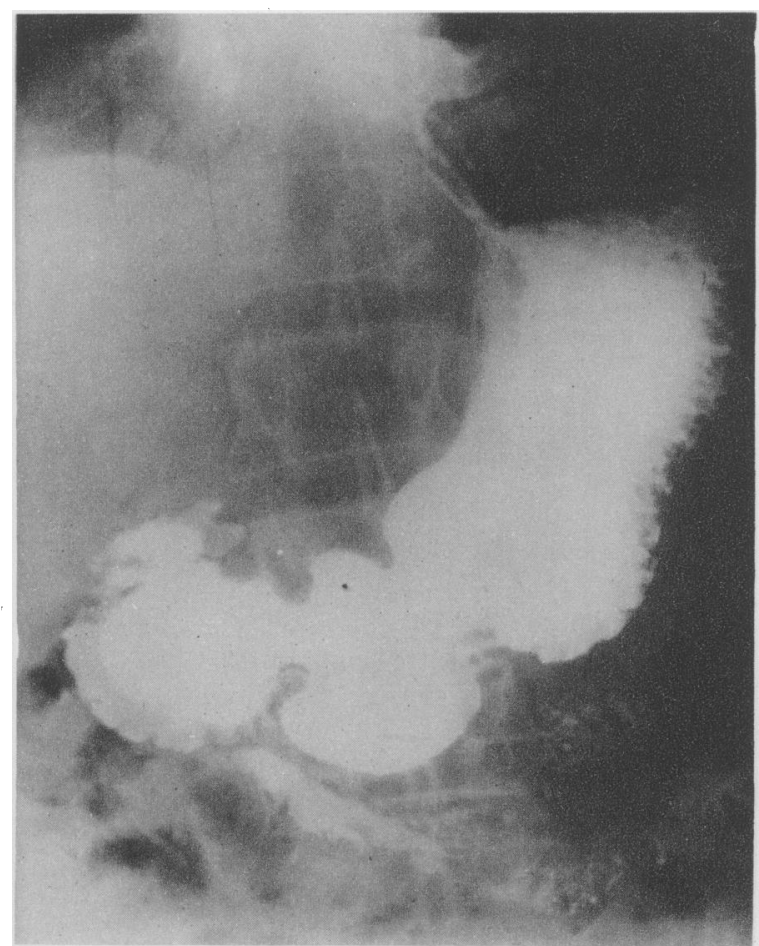

Fic. 3.-Sthenic type

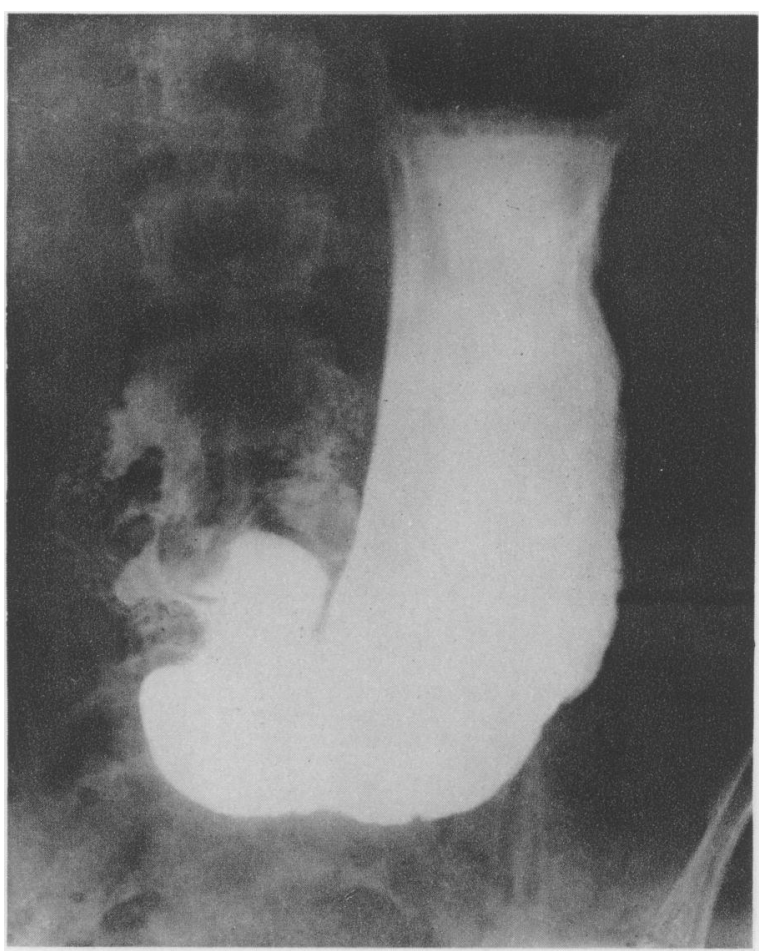

Fia. 2.-Hyposthenic type.

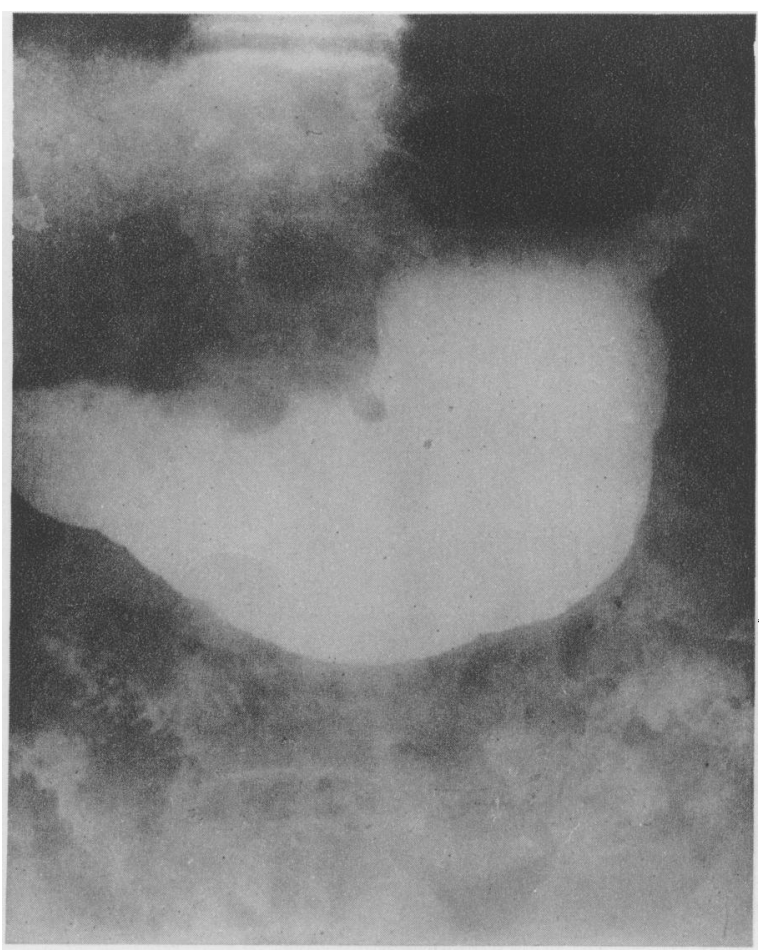

Fıa. 4.-Hypersthenic type. 